\title{
A Assistência nas Ordenações do Reino.
}

\author{
Moacyr Lobo da Costa \\ Docente livre de Direito Judiciário Civil, da \\ Faculdade de Direito da Universidade de \\ São Paulo.
}

1. Na tarefa hercúlea e monumental da codificação do direito português, iniciada no reinado de D. João I pelo famoso Corregedor "o mestre João Mendes" e terminada em 1446, no reinado de D. Afonso V, pela comissão de juristas presidida pelo corregedor Lopo Vasques, aproveitaram os compiladores as leis promulgadas desde D. Afonso II, as resoluções das côrtes, as concordatas celebradas por D. Diniz e D. Pedro, mas, como observou autorizado historiador daquêle direito, "a principal fonte, porém, foi o Direito Romano e o Direito Canônico, dos quais os compiladores extrairam títulos inteiros, além das muitas referências a um e outro, que a cada passo se encontram por todo o corpo desta obra". ${ }^{1}$

Com referência à intervenção de terceiros no processo pendente entre outras partes, com a finalidade de evitar o prejuizo decorrente da sentença, os compiladores das Ordenações Afonsinas acolheram, apenas, os princípios do Direito Romano sôbre a apelação do terceiro.

Não se encontra naquelas Ordenações qualquer texto a propósito da intervenção em primeira instância.

Da apelação de terceiro trata o tít. Lxxxv, do Livro mI - "dos que podem apelar das sentenças dadas entre as

1. COELHo DA ROCHA, Ensaio sôbre a história do Govêrno e legislação em Portugal, p. 118. 
outras partes" - reproduzindo os conhecidos textos do Digesto L. 49 tít. 1, sôbre a apelação dos herdeiros, legatários, fiadores etc., para proteção de seu interêsse contra o conluio das partes. São as mesmas regras de Ulpiano, Marciano e Macro que os compiladores traduziram e incorporaram nas Ordenações. O princípio é o mesmo: permite-se a apelação do terceiro, que não é parte no processo, quando seu interêsse fôr prejudicado pela sentença em virtude de dolo ou conluio das partes.

Essas normas, com ligeiras modificações de redação, foram reproduzidas nas Ordenações Manoelinas, do Livro III, tít. LXviI.

$\mathrm{Na}$ nova codificação promulgada pelo "O Venturoso", em 1521, também, a intervenção do terceiro prejudicado foi disciplinada, apenas, em grau de recurso, como apelação. Quanto à assistência, em primeira instância, depara-se, contudo, com uma referência incidente, no título que regula "a ordem do juízo", a demonstrar o reconhecimento dessa prática, não obstante os compiladores não tenham estatuído a seu respeito, destacadamente, como figura processual própria.

Nas disposições sôbre a assinatura de têrmo para razoarem os procuradores das partes, foi previsto que " $E$ se vier algum Assistente a cada huma das partes, ou for chamado por auctor, e quizer ajudar o reo, e cada hum quizer fazer seu Procurador, e não o que cada hum das partes tem feito, podel-o-hão fazer: porem não será assinado termo a cada hum dos ditos Procuradores per si, mas ajuntar-se-hão ambos os Procuradores, ou os mais que forem, e farão hum só razoado." (L. III, tit. xv, $\S 14$ ).

2. O acolhimento da Assistência, como figura processual própria, no direito português, ocorreu pouco depois da promulgação das Ordenações Manoelinas.

Trata-se de criação de uma lei extravagante, a célebre Carta Régia de 5 de julho de 1526, de D. João III, que estabeleceu a nova ordem do processo civil. Essa lei foi con- 
solidada pelo jurisconsulto Duarte Nunes dọ Lião, na "compilação" que realizou a mandado del rei Dom Sebastião, em 1569, e se tornou conhecida por "Código Sebastiânico".

Esse Código trata na Parte III, "das cousas judiciaes", dispondo no título 1 , L. $7, \S 29$ :

"E vindo algūa pessoa assistir a huma das partes, prosseguiraa o feito nos termos em que estiuer e se procederaa na assistencia, segundo direito e forma desta ordenação.” 2

O preceito foi reproduzido na lei de 18 de novembro de $1577, \S 15,{ }^{3}$ passando, depois, para as Ordenações Filipinas.

3. A possibilidade do terceiro interessado intervir na causa, como assistente, para obstar ao conluio das partes, já era proclamada por arestos judiciais, anteriores ao Código Sebastiânico. A êsse propósito Jorge DE CABEdo refere um Aresto do ano de 1560, e acentua "quod est maximé notandum". ${ }^{4}$

2. DuARte Nunes do Lĩ̃o, Leis extravagantes, collegidas e relatadas per mandado do muito alto e muito poderoso Rei Dom Sebastião, nosso Senhor, Coimbra, 1796, p. 335.

3. Cf. José Anastácio de Figueiredo, Synnpsis Chronologica de subsidios ainda os mais raros para a História é Estudo crítico da Legislação Portugueza, Lisboa 1790 t. II p. 181.

4. JoRGe DE CABEDo, "Decisionum Supremi Lusitanae Senatus", ULYSSIPONE, MDCIV, pars secunda, p 195: Arestum LXXXvi: No mesmo feito do Conde do Demira com Alvaro de Sousa, se moveo por duvida, se podia hum filho do dito Alvaro de Sousa, por nome Diogo Lopez de Sousa, e a quem por morte do dito Alvaro de Sousa seu pay vinhão as terras, que o Conde lhe demandava, assistir na causa ao dito seu pay, pello prejuizo, ou interesse, que se lhe seguia; por quanto o dito seu pay estava mal com o dito filho e se não falavão por inimizades que entre elles avia, e temiase o filho, que ouvesse da parte do pay algum concluio na demanda.

$\mathrm{E}$ determinou se, que podia assistir a seu pay, per causa das ditas inimizades e concluio que se presumia: e que os procuradores do pay: 
Dos juristas portuguêses dêsse periodo, Jorge de CABEdo foi o primeiro a tratar com autoridade e desenvolvidamente da assistência, baseando-se na doutrina dos glosadores e seguindo de perto, particularmente, a Covarrubias.

Encontram-se no seu famoso livro de Decisões alguns conceitos que iriam servir de fundamento, posteriormente, à doutrina dos comentaristas das Ordenações Filipinas, na interpretação do dispositivo que disciplinou a assistência. ${ }^{5}$

Ante a sabida circunstância de ter sido o jurisconsulto JoRge DE CABEDo um dos encarregados da compilação das Ordenações del rei Dom Felipe, - o principal compilador, ao ver de Candioo Mendes de Almeida ${ }^{6}$ - não parece desarrazoada a hipótese de se lhe atribuir a inspiração do texto que, naquêle monumento jurídico, os compiladores introduziram, a propósito da intervenção do terceiro interessado, em primeira instância, sob a forma de assistência, de par com a apelação do terceiro prejudicado de que trata o título LXXXI, do Livro III, nos mesmos casos já contemplados nas Ordenações anteriores.

"E vindo alguma parte assistir ao autor ou ao réo, será obrigado a tomar o feito nos termos, em que estiver, sem ser ouvido ácerca do que já fôr processado, posto que o pretenda ser per via de restituição, ou per outro qualquer modo. E se a assistência fôr depois de ser dada a sentença na mór alçada, poderá o assistente, per via de restituição, ou per outro modo jurídico, allegar contra a

e do filho, se ajuntassem ambos pera correr com o feito no mesmo termo: conforme a Ordin. do lib. 3 titul. 20. $\$ 41$. incipit, $\mathrm{E}$ posto que escrivão Pero Almirante, anno 1560. quod est maximè notandum.

Et vide ad illam Ordin. text. in 1. justissime, 44. D. de aediliti. edict. si familiae. 48. $u b i$ DD. D. fam. erciscund.

5. Ver, especialmente, a Decisio Xcvi, nrs. 13,14 e 15 , e a Decisio. CXIX n. ${ }^{\circ} 7$; in op. cit. pars secunda, p. 147 e p. 170.

6. CÂndido Mendes de Almetda, Auxiliar Jurídico, Rio de Janeiro, 1869, p. 616 nota 1; e Código Philippino, $14 .^{\text {a }}$ ed., Rio de Janeiro, 1870, p. XXVII. 
dita sentença o que lhe parecer ácerca do prejuizo, que ella lhe faz, sem o principal, contra quem se deu a sentença, ser mais ouvido como parte, nem se tratar de seu interesse.

E na assistencia se procederá na forma de nossas Ordenações e Direito". - Livro III, tit. xx n. ${ }^{\circ} 32$.

Para explicar êsse texto e suas implicações, os comentaristas socorreram-se dos princípios enunciados por CABEDo, em suas decisões, citando-o, seguidamente, ao lado de CoVARRUBIAS. 7

Silva, em duas páginas de seus comentários, "Ad § xxxII", cita-o dez vêzes ${ }^{8}$; ao expôr a regra de que o terceiro assistente não pode alegar nem provar sinão o que pode o principal, a quem defende e coadjuva, ainda que êsse terceiro seja menor, e peça por via de restituição, Silva declara, "ut expresse decidit textus noster", mas, repete a advertência de Mendes, nas anotações a Castro, "quod secus est de jure communi, secundum quod loquutus est Cabedo, 2 p. ảecis. 97 n. $15 "$; e, ao tratar da assinatura do têrmo para

7. Confira-se, a título exemplificativo: CABEDo escreveu “\& ob hoc si contingeret, quod in causa partes citanda sint, quia elapsis sunt sex menses quod acta dormiunt, quando actor citatur \& reus etiam citari debet adsistens uni ex illis, per doctrinam BALDI," - Decisio CXIX, n.ò 7, op. cit. p. 170; PEGAS repetiu: "Nota, quod talis assistens dicitur pars in causa, et ideo post lapsum sex mensium debet citari, Cabed. 2 p. D. 119 n. 7" - Manoel Alvares Pegas, "Commentaria ad Ordinationes", tomus decimus quintus, Ulyssipone, MDCcLIX p. 71; e, também, Suva: "Nota etiam, quod quando partes sunt citandae, quia elapsi sunt sex menses, quod acta dormiunt, citari debet etiam assistens una cum actore, \& reo. Caed. 2 p. decis. 1 n. 13 (sic, deve ser êrro de impressão; o certo é decis. 119 n. 7) ubi tenet, quod ad singulos actus citari debet assistens." - MANoel Gonçalves DA Silva, Commentaria ad Ordinationes, tomus primus, Ulyssipone MDCCXLI, n. ${ }^{0} 17$, p. 108 . Ver, também, Jeronymo Pereira DA Silva, Repertorio das Ordenações, Coimbra MDCCLXXXXv, tomo 1 p. 242 nota $b$.

8. Manoel Gonçalves da Silva, op. cit. pp. 107 e 108.

9. Manoel Gonçalves DA Silva, op. cit. n. 4 p. 107. 
razoarem os procuradores das partes, no $\S 41$, onde se declara "e se vier algum assistênte", SiLva comentou: "Decidit textus, quod tam Advocato assistentis, quam partis, cui assistit, unius tantum terminus assignatur, in quo ambo simul unicam faciant allegationem; ita judicatum refert CABEDo, 2 part. arest. $86 " 10$

De igual modo Mendes de Castro ${ }^{11}$, ao dissertar sôbre o processo civil em primeira instância, cita-o, ao lado de Covarrubias, a propósito do "De tertio assistente".

E o grande Mello Freire, na sua exaustiva definição de assistente, que de tão repetida pelos pósteros tomou visos de clássica, invoca, por duas vezes, a autoridade das decisões de CABEDo, para delinear os contornos daquela figura processual.

"Adsistens, qui et suam, et alienam causam defendit, is dicitur, qui judicio adcedit actoris, vel rei adjuvandi gratia, veluti filius patri in causa majoratus, Cabed. P. II, Arest. Lxxxvi; dominus directus emphyteutae in causa ephyteutica; venditor emptori, a quo res vendita et tradita petitur; et omnes denique auctores, qui in alium rem suo nomine quocumque titulo oneroso transtulerunt, reo super eadem convento, Ord. lib. 3. tit. 45 (Tit. Iv $\S \mathrm{xII}$ ).

Adsistens et ante et post litem contestatam intervenire potest, imo et post sententiam, quae in rem judicatam non transiit, causam tamem, et processum in statu, quo est, adsumit; nec admittitur, quin statim summarie probet sua interesse, ut liti adjun-

10. ManOel Gonçalves da Silva, op. cit. p. 115.

11. Manoel Mendes de Castro, Practica Lusitana, tomus primus, Conimbricae, MDCCXXxIx, p. 352 - dêsse autor disse PONTES DE MIRANDA ser "o maior dos processualistas de Portugal e do Brasil".

"Comentários ao Cád. de Processo Civil", 2." ed. Rio de Janeìro 1962 , tomo Xv p. 356. 
gatur, ne illius protrahendae causa obtrudi videatur, Ord. lib. 3 tit. $20 \S 32$, cap. ult. ut lit. pend. in 6; Cabed. P. II, Decis, $97 \S \S 13.14 .15{ }^{\prime} 12$

Tais indícios militam em favor da hipótese aventada. Concorre, ademais, o fato de Pedro Barbosa, o "insigne", a quem Mello Freire ${ }^{13}$ atribui a primazia entre os compiladores das Ordenaçôes Filipinas, só ter escrito sôbre a assistência, após a promulgação das Ordenações, em seu livro de comentários para a interpretação da lei "De iudiciis", publicado em $1613^{14}$, e dos outros compiladores e revisores não terem se ocupado com os problemas jurídicos da assisténcia, em seus escritos.

Este eminente jurisconsulto, ao discorrer sôbre a "Legis Venditor $\operatorname{xxxxix,De~iudiciis"~}{ }^{15}$, examina e discute as várias questões que se apresentam com a intervenção do vendedor, como assistente, na causa entre o comprador e o reivindicante da coisa vendida, assentando algumas regras que serviram, também, para a posterior elaboração da teoria processual da assistência no direito português. ${ }^{16}$

4. De notar-se que, tanto Jorge de Cabedo como Pedro BARBosa, os dois principais compiladores das Ordenacooes Filipinas, escrevendo sôbre a assistência, por sua vez, fundamentam sua opinião, de maneira explícita, na doutrina dos glosadores, mas, o autor mais freqüentemente citado, em cuja lição procuram apoiar os conceitos que vão emi-

12. PASChOAL JosÉ DE MELlo FreIRe, Institutiones Juris Civilis Lusitani", editio quinta, Conimbricae, 1853, liber Iv, p. 125.

13. Paschoal José de Mello Freire, Historiae Juris Civilis Lusitani, Ulyssipone 1788 § XIII p. 102.

14. Pedro Barbosa, Commentarii ad interpretationem Tituli ff. De iudiciis, Ulyssipone 1613.

15. Pedro Barbosa, op. cit. p. 328.

16. Pedro Barbosa, op. cit. ver, particularmente: nrs. 103, 119, $120,121,123,124,125,136,137,140,165,177,178$ e 179, de p. 332 a 337 . 
tindo e firmando, ao longo de suas páginas, é o célebre Diego de Covarrubias. Cabedo, na mesma decisão, cita a Covarrubias cinco vêzes, inclusive para contrapôr sua doutrina à de BARToLo. ${ }^{17}$

Pedro Barbosa, igualmente, num mesmo comentário, cita a Covarrubias duas vêzes, em abono de sua interpretação. ${ }^{18}$

Covarnubias, que foi o maior jurista espanhol do século xvi, cognominado o "Bartolo espanhol", exerceu, com seus escritos, enorme e preponderante influência sôbre o direito de tôda a península e não apenas de sua Pátria.

17. "Item adsistens est quodammodo consors ejusdem litis, \& assumit causam in eo statu, in quo est, cum ipse ad illam accedit sive vltro sive vocatus, ut est Ord. expressa tit. 20 \$ 32 . quae videtur desumpta ex text. in cap. ultimo ut lite pendente. lib. 6 de quo late Covarr. pract. cap. 13. a n. I. Idque etiam si adisistentis intererit causae defensio, secundum aliegatos à Covarr. ibdem. \& ideo potest allegare, \& probare omnia, quae principalis nom allegavit, nec probavit. Gloss. communiter recepta in 1. si suspecta. D. de in offic. testam ubi Angel. Perus. Colum. 2. Covarruv. ubi supra, coluna. 3 vers. primum ex his."

"Insertur etiam ex supradictis, quod iste adsistens non poterit allegare, nec probare, quae principalis eo tempore jam non potest; \& ideo non potest testes producere in judicio post publicationem attestationum, ac denique eo tempore, quo non possit reus ipse principalis, etiam si adsistens ignoravit causam agi, testes produci, ex Covarruv. ubi supra, colum. 3. versicul. secundo hinc apparet num. 2. cum Innocent. \& Anton. in cap. cum super. de re judic. \& allis, quos refert, \& sequitur contra Bartol-Abb. Felinum \& alios, ex eo quia debet assumere causam in eodem statu, ut pars, \& litis consors, cui praejudicium imminet, si reus ipse sit victus, \& per sententiam condemnetur. Et ibi denique tenet, \& vehementer asseverat, non licere adsistenti allegare quae principali de jure non licent, eo tempore quo assumit causam. Quod tamen fallit, nisi jadsistens sit minor, quia per restitutionem licebit illi ea allegare, \& probare, quae principalis non potest, cui quidem ad hoc proderit ipsius minoris impetrata restitutio, secundum Covarr. quest. 14 col. 8." JORGE DE CABED0, op. cit. p. 147.

18. 124 - "Si autem compareat, post finitam dilationem concessam emptori ad probandum cum debeat assumere litem in terminis in quibus erat tẽpore assistentiae, ut dictum est, non poterit hoc casu novas probationes facere, quantumcunque alleget, se ignorasse dilationem 
Em Portugal, atestam a assertiva as abundantes e freqüentes citações de sua opinião, especialmente, a propósito da assistência, que fazem os decisionistas e comentaristas. ${ }^{19}$

Não será descabida, pois, a afirmação de que a doutrina portuguêsa da assistência foi construida a partir dos ensinamentos do eminente jurista hispânico.

Em vez de traduzirem diretamente dos textos romanos, do Digesto e do Código, como o fizeram para a apelação do terceiro prejudicado, os juristas portuguêses do século Xvi e começos do xviI, que elaboraram os preceitos a propósito da intervenção do terceiro interessado na demanda, em primeira instância, sob a forma da assistência, foram buscar nas lições do "Bartolo espanhol" os característicos dessa espécie de intervenção de terceiro, transplantando-os para o direito português.

5. No livro consagrado ao exame de questões práticas, Covarrubias dedica um longo capítulo ao problema do terceiro opositor e à discussão das opiniões de Bartolo, Baldo, Inocêncio e outros, com a seguinte epigrafe: "Quid sit praecipué observandum ubi qui nondum litigavit, litis \& causae examini sc offerat: quem tertium oppositorem dicimu's" 20.

datam emptori ut cõtra multos prob. \& resolvit Covar. practicarum quaestionum cap. 13 nu. 2; 125 - nisi assistens sit minor, qui beneficio restitutionis impetrabit posse producere novos testes glos. 1. si parentes verb. ex persona Cod. de evictio. Covar. practicarum cap. 14 nu. 3." - Pedro Barbosa, op. cit. p. 333.

19. Cfr. além de Cabedo e Barbosa, mais Manoel Gonçlyes da Silva, op. cit. pp. 107 e 108; MANofl Alvares Pegas, op. cit. p. 71; Manoer Mendes de Castro, op. cit. pp. 54, 55; Jeronymo Pereira DA Silva, op. cit., tomo 1 p. 242, nota b.......

20. Diego Covarrubias, Opera, Lugduni, mdxviII, tomus primus, "Practicarum Quaestionum", cap. XIII, p. 852 - Summarium:

1 Tertius oppositor \& litis defensor lad coadiuvandum admissus, assumere debet litẽ in eo statu quo erat.

- 2 Tertius oppositor ad coadiuvandum non potest post pu. blicationẽ, \& conclusionem testes producere. 
Por se tratar de obra extremamente rara, de difícil consulta, reproduzimos a parte introdutória dêsse capítulo, que é fundamental para o estudo da história da assistência no direito das Ordenações:

"Saepissime contingit duobus in iudicio litigantibus tertium quemdam litis, \& causae examini se ipsum opponere, \& offerre.

Etnim vult hic tertius causam illã vel prosequi, vel defendere: quod multis modis accidere potest. Quorum aliquod nos hoc in loco examinabimus ea ex causa, quod passim viderimus de hac re in supremis Regis tribunalibus satis controverti. Illud veró receptum est, diúque obtinuit, hunc tertium, qui se liti opponit, admittendum esse hoc sanè modo, ut quoties is litem adsumat ad coadiuvandum reum, vel actorem, utque ei adsistat: tunc in eo statu causam prosequatur, quo prosequebatur ipse principalis. At sit ad iudicium accesserit hic tertius non ad coadiuvandum alium, sed ad excludẽdum utrunq à rebus vel à iuribus, de quibus agitur: eo quidem casu admittitur hic ad causam agendam ab. initio, ita quidem, ac si ab alio cepta nõ esset:

3 Intellec. 1. si suspecta ff. de inoffic \& an procedat illud responsum ignorantibus legatariis.

4 Res inter alios acta in iudicio, aliis praeiudicat \& prodest quoad quandam praesumptionem.

5 Sententia inter alios dicta plerunque ex propria vi \& natura nocet \& prodest omninò aliis: \& ibi latè intellect. 1. ingenuum ff. de statu homi.

6 Sententia lata super primogenito cum legitimo contradictore, an aliis noceat?

7 Traditur latè interpretatio text. in 1. saepe. ff. de re iludic. in ver. sed scientibus.

8 Intellectus ad text. in cap. penult. de re iudic.

9 Intellectus ad text. in d. 1. saepe. ver. nam et si libertus: \& inibi an sententia lata contra vassallum, praeiudicet. domino scienti. 
omniáq; sunt cum hoc repetenda: nec tenetur hic tertius causam in eo statu adsumere, quo ea quidem erat inter ipsos duos, cui medius hic accedit, tempore oppositionis. Haec distinctio summa denique est totius huius tractatus : \& tamen habet adeò dubias $\&$ frequentes quaestiones, ut operae precium sit eam explicare paulò diligentiùs, maximè ad veram interpretationem eorum, quae Bartol. Innocent. \& alii hac de re hactenus tradidere.

Prior veró distinctionis pars probatur in cap. ult. ut lite pend. in vj. sic enim ibidem respondetur sanè si ad defensionem ipsius litis aliqui, quorum intererit, petierint admitti: eos in illo statu, in quo ipsam inveneriunt decernimus admittendos. Haec ibi: ex quibus manifestū sit, non esse tertium admittendum, ut novum causae cõsequatur: si ipse accesserit ad defensionem alterius, qui iam causam fuerat prosequutus: imó tenetur, etiam si defensio eius intererit, in eo statu causam prosequi, in quo erat tempore oppositionis. Atque ita visum est Felino in cap. cùm super nume. 15 de re iudic. Baldo in auth. nunc si haeres," etc.

Idem ex d.c. ulti. adnotavit Sebastianus Vantius de nullitati. tit. quis possit dicere de nullitate. num. 25. extat exemplum huic oppositioni de vẽditore, qui tenetur de evictione: nam hic opponit se saepissimé liti. \& controversiae motae contra emptorẽ super re vendita, l. veditor ff. de iudic. l. a sentencia \& d.l. si perlusorio ff. de appellat. idem erit in legatariis defendentibus scriptum haeredem in lite, quae ad testamentum rescindendum adversus ipsum proponitur in d.l. si suspecta. Sunt \& alia multa exempla praesertim ex. l. saepe ff. de re iudic. authen. tunc. si haeres. C. de litigio. l. Paulus ff. de procura. 1. si pariter ff. de liberali caus. cap. ij. de proci. in vj. cap. ut circa de elect. in vj. Clemen. constitutionem de clectione. Igitur quoties venditor 
ad iudicium accedit defensurus emptorem, contra quem agitur pro re vendita, adsumere debet litem in eo statu, quo erat tempore oppositionis. Quod \& de similibus exemplis dubio procul respondendum erit: qua ratione plures deduci poterunt, quae sunt in praxi maximé notanda ad rectum iustitiae ministerium, \& ut calumniis occurramus, quae facilimé contingunt in his oppositionibus: cum plerunque fiant potiús iniuria \& malitia, quam iure."

Sem pretender comentá-los - o que seria inoportuno neste trabalho de investigação histórica - importa, todavia, -ressaltar os aspectos dominantes da exposição, quanto à fundamental distinção ențre o terceiro que assume a lide, como assistente, para coadjuvar o autor ou o réu, e o que ingressa no feito, não em auxílio de outrem, mas para excluir os demandantes, por motivo da coisa ou do direito sôbre que se litiga. Também, quanto aos exemplos apontados, todos de origem romana, cuja precípua finalidade prática, segundo Covarrubias, seria o reto ministério da justiça, para prevenir a má-fé, que mais fàcilmente ocorre nessas oposições; já que, em muitos casos, surgem mais por malícia e sem razão do que por direito.

6. No texto das Ord. Fil. L. III, XX, 32, os compiladores cempregaram as denominações de assistente e assistência, para o terceiro que intervem no processo e para a figura de sua intervenção, já consagradas na legislação extravagante anterior, a exemplo das fontes romanas, - Dig. 3, 3, 69 e 5, 2, 29; Cod. 4, 48, 1 e 8, 45, 20, ${ }^{21}$ — ao contrário do que se verificou na legislação dos principais países da $\mathrm{Eu}-$ uropa ocidental, como a França, Itália e Alemanha, em que, :sob a influência da doutrina dos glosadores do direito comum, o legislador adotou a terminologia por êstes divulgada.

21. Cf. nosso trabalho Origem Romana da Assistência na Rev. da Fac. de Direito, vol. LIX p. 152. 
$\mathrm{Na}$ doutrina construida pelos glosadores distinguiam-se: três espécies de intervenção: $1^{\mathrm{a}}$ — "interventio ad infringendum jura competitorum"; $2 .^{\mathrm{a}}$ — "interventio ad coadjuvandum reum vel actorem"; $3,{ }^{a}$ - "interventio post sententiam ad ejus executionem impediendam".

Essa distinção é justamente atribuída a Bartolo. ${ }^{22}$

Em seus comentários ao Digesto, 49, 1, 14, pr. Bartolo. escreveu: "Videmus quod possit facere tertius qui venit ad causam per alium incoeptam. Circa quod est sciendum quod tertius potest venire ad triplicem effectum. Quandocunque venit ad impediendum ne causam ille qui incoepit agat, seu defendat; quandocunque venit ut ei assistat et probationes inducat et alia faciat ad victoriam consequendam; quadocunque venit post sententiam ad impediendam executionem". ${ }^{23}$

Sem embargo de Bartolo ter escrito adequadamente, a propósito, "quandocunque venit ut ei assistat", a doutrina corrente denominou "interventio ad coadjuvandum", a essa figura, como se lê na generalidade dos autores da época.

Assim, em lugar da assistência romana, os glosadores passaram a dissertar sôbre a "interventio ad coadjuvandum".

A lição dos glosadores, repetida pelos escritores dos vários países europeus, acarretou a abolição do emprêgo de assistência, de genuina procedência romana, e sua substituição por "interventio", criação do direito comum da idade média que o direito romano desconheceu.

$\mathrm{Na}$ França, antigos escritores e repertórios de costumes jurídicos definiam-na: "La demande d'intervention est, lorsque dans une instance formée entre deux particuliers survient un tiers dans l'instance, soit pour prendre le fait et cause du défendeur, ou pour quelque intérêt particulier et différent de celui des parties, mais qui y a rapport" "Nouveau Style du Châtelet de Paris", L. l, t. II, Intervention.

22. Giunio Sabbatini, Su L'Intervento in causa, Roma 1880 p. 15.

23. Bartolo de Saxo Ferraio, In Primam et Secundam, Venetiis 1570, IV, p. 211, de Appellationibus et relationibus Dig. 49, 1, 14 pr. 
Segundo Denizart, "les praticiens nomment partie intervenante celle qui survient dans une cause civile pour $\mathrm{y}$ prendre part, pour conserver les intérêts du defendeur ou les siens propres." 24

Das "Ordennances" de Abril de 1667 (título XI, art. 28) ao Côde de Procédure Civile (arts. 339, 340, 341, 406), "intervention" é o têrmo consagrado pelo legislador.

$\mathrm{Na}$ Alemanha um antigo escritor definia: "Actus, quo quis aliena liti sponte se immescet, interventio dicitur" ${ }^{25}$, e da "intervenção de terceiros no processo" trata o z.P.o., de 1877 , no livro I, sec. II, tit. II, $\$ \S 64$ a 77 , denominando de intervenção adesiva no $\S 66$, (Nebenintervention) a intervenção "ad adjuvandum" do direito comum. ${ }^{26}$

No direito italiano o têrmo "intervento accessorio" é tradicionalmente empresado e de uso corrente na doutrina, a partir dos jurisconsultos do século xiv, tendo superado por completo a assistência cujo conceito, no dizer de SEGNI 27 "non è portato ad alcun contributo nella costruzione sistematica dell'intervento".

O direito português, todavia, manteve-se fiel à terminologia romana, no que foi seguido pelo direito brasileiro.

24. Apud Henri Blavot, De L'Intervention, tese, Paris 1897 p. 17 e JeAN Henriot, De L'Intervention, Dijon 1903 p. 23.

25. L. B. Claproth, De Interventione libellus, Goettingae 1763, cap. III § 34 - FREDERICO GLÜCK, Commentário alle Pandette, trad. Brugi, Milano 1893, Livro v p. 265.

26. As expressões "nebenintervention" e "nebenintervenient", empregadas nos $\S \S 66,67$ e 68 do ZPo, significam "intervenção adesiva" e "interveniente adesivo", como foram traduzidas para o italiano por Ludovico Euzesio, (Ordinamento della Procedura Civile Germanica, Torino 1899, p. 12 e 13) e para o castelhano por L. PRIETo CASTRo, apêndice ao Derecho Procesal Civil de J. GolDschmidt, ed. Labor, 1936, p. 781), e não "assistência" e "assistente", como as traduziu LOPES DA Costa (Da Intervenção de Terceiros no Processo, S. Paulo 1930 p. 96).

27 Antonio Segni, Lintervento Adesivo, Roma 1919, p. 67. 
7. A intervenção voluntária de terceiro no processo. entre as partes, com a finalidade de assistir ao autor ou ao rèu, foi disciplinada, expressamente, nas Ordenações Filipinas, do Livro III, tit. $\mathrm{xx}, \mathrm{n} .^{\circ} 32$ :

" $E$ vindo alguma parte assistir ao autor ou ao réo, será obrigado a tomar o feito nos termos, em que estiver, sem ser ouvido acerca do que já for processado, posto que o pretenda ser per via de restituição, ou per outro qualquer modo. E se a assistencia for depois de ser dada sentença na mór alçada, poderá o assistente, per via de restituição, ou per outro modo jurídico, allegar contra a dita sentença o que lhe parecer acerca do prejuizo, que ella lhe faz, sem o principal, contra quem se deu a sentença, ser mais ouvido como parte, nem se tratar de seu interêsse. $E$ na assistencia se procederá na forma de nossas Ordenações e Direito."

A assistência destinava-se, em seu primórdio, a obstar o conluio entre as partes com o objetivo de causar prejuizo ao terceiro.

Com essa finalidade foi a figura da assistência conhecida no direito romano, do período imperial da "cognitio extra ordinem". ${ }^{28}$

Em Portugal, também, uma das mais antigas decisões judiciais, que se conhece a respeito da assistência, proclamou, explicitamente, a mesma finalidade. ${ }^{29}$

O terceiro era admitido a ingressar no processo, como assistente de uma das partes, desde que alegasse interêsse de impedir o presumível conluio das partes em seu prejuízo, tal como fora estabelecido no direito romano: "Si suspecta collusio sit legatariis" Dig. $5,2,29 \mathrm{pr}$.

28. Cf. nosso trabalho "Origem Romana da Assistência", na Rev. da Faculdade de Direito de S. Paulo, vol, LIX, p. 152.

29. JoRGe DE CAREDO, "Decisionum Supremi Lusitanae Senatus", Ulyssipone, MDCrv, pars secunda, p. 195, Arestum Lxxxvi. Ver o inteiro teor dessa Decisão na nota 4 . 
A finalidade própria da assistência traduzia-se na fórmula "ne fiat collusio."

Intervindo no feito, como assistente, o terceiro vinha coadjuvar a parte assistida, na defesa da causa, em que tinha, também, interêsse próprio.

Para legitimar a intervenção não bastava o simples interêsse na vitória de uma das partes, mas era necessário que o terceiro tivesse interêsse próprio nessa vitória.

Nos comentários a essa ordenação escreveu SiLva: "Agitur in hoc textu de secunda specie tertii oppositoris, quae contingit quando tertius comparet pro suo interesse ad coadjuvandum scilicet reum, vel actorem, utque eis assistat;" etc. ${ }^{30}$

Cento e muitos anos antes, o insígne Pedro Barbosa, dissertando sôbre a lei "De iudiciis", assentara a regra de que o assistente na lide, "propter propriu interesse", é considerado como autor e deve seguir o fôro do réu, e que, o assistente na lide, "propter propriu interesse", pode opôr as exceções que o comprador omitiu, ou que não quiz ou não pôde opor, reconhecendo, assim, a existência de interêsse próprio na assistência. ${ }^{31}$

Em consonância com êsse entendimento da doutrina sustentada pelos mais autorizados expositores do direito Filipino, Mello Freire elaborou sua clássica definição de assistente:

"Adsistens, qui et suam, et alienam causam defendit, is dicitur, qui judicio adcedit actoris, vel rei adjuvandi gratia, etc.. ${ }^{32}$

30. Manoel Gonçalves DA Silva, "Commentaria ad Ordinationes", tomus primus, Ulyssipone MDCCXLI, ad § XXXII p. 106.

31. Pedro Barbosa, "Commentarii ad interpretationem Tituli ff. De iudicii" Ulyssipone 1613, p. 332, n. ${ }^{\circ}$ 103: "Accedat quod assistens liti propter propriu interesse. consideratur tanquam actor \& ideo debet sequi forum rei, ut prosequitur"; p. 337 n. ${ }^{\circ}$ 178: "Quod assistẽs liti propter proprium interesse, potest opponere exceptionem, quã emptor omisit opponere, vel quia noluit, vel quia non poterit."

32. Paschoal José de Mello Freire, "Institutiones Juris Civilis Lusitani", editio quinta, Conimbriae 1853, p. 125. 
Aquêle que defende a sua e a alheia causa.

8. Tema controvertido entre os antigos Praxistas era, não só, o da natureza, como o da prova do interêsse para legitimar a assistência.

JoÃo Mendes Junior dedicou ao assunto um breve, mas erudito, estudo doutrinário, examinando as duas correntes de opinião que se formaram: de um lado, Pereira e Souza, Maranta, França ad Mendes e Silvà exigiam que o assistente provasse logo o interêsse que tinha na causa, e, de outro, Mendes a Castro, Mello Freire e Almeida e Souza, argumentando que, se para apelar, de acôrdo com a Ord. L. III, tit. 81, basta que o terceiro "aliqualiter et apparenter" mostre o seu prejuizo ou interêsse, com maioria de razão é isso bastante para ser admitido à assistência; "quamquam interesse solum sit apparens seu coloratum", diziam êsses autores, e, acrescentavam, que, "melius est ante tempus ocurrere quam post remedium quoerere." 33

Silva era categórico: "Debet tamen talis tertius, priusquam admittatur, ostendere interesse, quod habet in causa." 34

Em sentido contrário argumenttou LoBÃo, argutamente: "Ainda que aqui o A. (Pereira e Souza) no fim da Not. citando a Maranta e França a Mendes exige no Assistente, para ser admitido, provar logo o seu interesse, que tem na defesa da Causa; eu julgo, que não he precisa huma rigorosa prova, mas basta que "aliqualiter, et apparenter" mostre o seu prejuizo, ou interesse; porque não ha differença em ser admitido, como Terceiro Assistente no progresso da Causa, ou appellar depois da Sentença; e se para appellar, como Terceiro, basta que "aliqualiter, et apparenter" dê fumos do seu prejuizo, ou interesse, Silv. ad Ord. L. 3 T. 81 in Pr. n. ${ }^{\circ} 29$, Schettin. de "Tert. ven. ad causa"

33. JoÃo MENDES JÚNIOR, "O interêsse da assistência", em Rev. dos Tribunais, vol. $3 \mathrm{p}, 289$.

34. Manoel Gonçalves Da Silva, op. cit. p. 107. 
P. 2 Cap. I. Da mesma forma quando vem assistir no progresso da Causa; aonde diz Hontalb, "de Jure superven." Tom. 1 Q. 26 n. $^{\circ}$ 2, que deve ser admitido, "quamquam interesse solum sit apparens, seu coloratum." 35

JoÃo Mendes Junion, embora escrevendo no Brasil, na vigência do Regulamento $n^{\circ} 737$, de 1850 , que, a seu ver, acabara a questão, determinando expressamente, no art. 124, que, para o assistente ser admitido, basta alegar o interêsse aparente, mesmo assim, tomou partido na disputa doutrinária e manifestou sua opinião: "A causa da assistência, em suma, é a existência do interêsse, seja êste direto ou indireto, imediato ou mediato; por outra, - desde que haja um prejuizo, ainda que não seja direto e imediato, a assistência deve ser admitida." 36

Do mesmo modo, José A. Almeida Amazonas, dissertando sôbre a assistência, depois de referir a controvérsia entre os Praxistas, reproduzindo, em linhas gerais, o estudo de JoÃo Mendes Júnion, conclui que, a seu ver, a razão estava com LoBÃo. "Com efeito, se era permitido a qualquer terceiro apelar de sentença proferida em causa estranha, para a qual não fora citado e na qual nem por qualquer forma interviera, desde que se sentisse prejudicado, conforme a ordenação do livro $3 .^{\circ}$ tit. $78, \S 10^{\circ}$ e tit. 81 princípio, razão não havia para que se prohibisse a sua intervenção antes da sentença, como assistente, uma vez que recebia a causa nos termos em que a encontrava. "Melius est ante tempus occurrere quam post remedium quoerere." 37

LoBÃo, com a acuidade que lhe era peculiar, antecipava-se na construção da figura do moderno assistente litisconsorcial, st'stentando, em contraposição à "communí opinio" que, "não só pode assistir na Causa aquelle, que tem hum direito auxiliante do A. ou R.; mas aquelle, que tem

35. Manoel de Almeida e Sousa de Lobão, "Segundas linhas", Lisboa 1855 , parte 1 , nota 173 , p. 48.

36. JoÃo MENDES JUNIOR, op. cit. p. 290.

37. José A. Almeida Amazonas, Assistência, tese, S. Paulo 1936, p. 27. 
hum Direito próprio e primário, occorrendo a que na Causa entre outros se lhe não maquine, ou della lhe não resulte algum prejuizo consequente". 38

Essa lição não prevaleceu. Enquanto estiveram em vigor as Ordenações Filipinas o entendimento dominante era no sentido de não admitir que o assistente alegasse direito próprio e primário.

Entendia-se que o assistente devia ter interêsse próprio na vitória do assistido e que, por isso, coadjuvando-o na defesa da causa, estava defendendo a sua própria, mas, não se lhe permitia pleitear por direito próprio e primário.

$O$ interêsse que legitimava a assistência é que, sendo próprio, podia ser primário ou secundário. O interêsse, não o direito do terceiro.

PÉGAS refere, a propósito, a seguinte resolução: “nam quocumque tempore, quo tertius venerit ad juditium pro suo interesse, non solum primario, sed etiam secundario admittendus est, ex ipsa Ord. L. 3, tit. 20 § 32, maximé dum sententia non est extracta à processu." 39

E Silva doutrinava em seus comentários, de maneira terminante: "Sed hujusmodi tertius non potest allegare, neque probare, nisi id, quod potest principalis, quem ipse defendit \& coadjuvat;" 40

$O$ direito que o assistente defendia na causa era o do assistido, mas fazia-o, por interêsse próprio.

9. A respeito das questões que ocorriam de ordinário no processamento da assistência vigoravam as seguintes regras, expostas pela generalidade dos autores, praxistas, comentadores e decisionistas: ${ }^{41}$

38. Manoel de Almeida e Sousa, de Lobão, op. cit. p. 47.

39. Manoel Alvares Pegas, "Resolutiones Forenses", Ulyssipone MDCCXXXvi, tomus sextus, cap. 131, n. ${ }^{\circ} 247$.

40. ManOel Gonçalves Da Silva, op. cit. p. 107.

41. Cf. Diego Covarrubias, "Opera", Lugduni, mdcluviir, tomus primus, "Practicarum Quaestionum", cap. XIII p. 85¿, cap. XIV p. 865; JoRge DE CABEDo, op. cit. pp. 147, 170, e 195; PEDRo BARBosa, op. cit. 
O terceiro podia assistir na lide mesmo contra a vontade do assistido;

o assistente devia assumir a causa no estado em que se encontrava, no momento da intervenção;

ao assistente não era permitido declinar do juzo, mas, quando o terceiro comparecia em tempo hábil para oferecer a exceção de incompetência do juízo em relação à parte principal, podia fazê-lo;

o assistente podia alegar a suspeição do juiz;

a Fazenda Real e o Fisco, quando ingressavam no feito como assistente, podiam declinar do juízo para o seu fôro privilegiado;

o assistente não podia inovar ou mudar a ação, contra a vontade do autor principal;

o assistente podia alegar e provar tudo o que o assistido podia faze-lo e ainda que por êste fosse omitido;

o assistente podia reconvir ao autor, se o réu não o fizesse;

depois da publicação dos depoimentos, o assistente não podia produzir testemunhas em juízo, ainda que ignorasse estar sendo discutida a causa; a não ser no caso do menor, que pleiteasse o benefício da "restitutio in integrum";

pp. 332 a 337; MAnoel Mendes de Castro, "Practica Lusitana", Conimbricae MDCcXXXIX, tomus primus, pp. 54 a 55; MANOEL PEgas, "Commentaria ad Ordinationes", Ulyssipone MDCcLIX tomus decimus quintus, p. 71; "Resolutiones Forenses", vol. cit. n. ${ }^{\circ}$ 104; MANOEL GonçALves DA Silva, op. cit. pp. 106 a 109; tomus tertius, p. 191 nrs. 6 e 9; JeroNymo da Silva Pereira, "Repertorio das Ordenações e Leis do Reino de Portugal", Coimbra 1795, tomo primeiro p. 242, nota b.; ANTONIo VANGUterve CABral, "Practica Judicial", Coimbra mDccxxx, parte V. cap. viI, p. 369; Melchior Phambo, "Decisiones Senatus Regni Lusitaniae", Conimbricae MDCcxxxvr, tomus secundus, Arestum V, p. 419; J. H. CorrêA Teldes, "Manual do Processo Civil", Coimbra 1849, p. 197. 
finalmente, o terceiro podia apelar da sentença, mesmo que o assistido não o fizesse.

10. A assistência podia ter lugar, sem qualquer restrição legal, em tôdas as causas, sempre que o terceiro tivesse interêsse próprio na vitória de uma das partes e se destinava a impedir o conluio entre as partes com o fito de prejudicá-lo.

A título de exemplo, os Praxistas indicam algumas causas em que foi admitida a assistência, nos primeiros anos da introdução dessa figura de intervenção de terceiro no processo, no direito positivo da monarquia lusitana, seguindo a lição dos maiores: Cabedo e Pedro Barbosa.

Mello Freire, na sua famosa definição de assistente, exemplifica: "veluti filius patri in causa majoratus, CABEDo P. II, Arest. Lxxxvi; dominus directus emphyteutae in causa emphyteutica; venditor emptori, a quo res vendita et tradita petitur; et omnes denique auctores, qui in alium rem suo nomine quocumque titulo oneroso transtulerunt, reo super eadem convento."

LOBÃo arrolou mais alguns exemplos, colhidos em outros autores como Schetrino e PÉGAS, assim: "na causa da nullidade de hum Testamento entre o herdeiro Escripto, e o Legitimo podem os Legatarios assistir para evitar alguma collusão entre os Contendores.

Se o Testador legou huma cousa litigiosa, como póde legar, sendo o herdeiro obrigado a prosseguir a demanda ex Ord. L. 4 tit. $10 \$$ fin, tem o Legatario faculdade de assistir a essa demanda, para evitar algum conluio.

Se antes de partilhas por Inventario hum Terceiro adquirio, por qualquer título, a parte hereditaria de hum Co-herdeiro na herança dividunda, pode e deve este Terceiro ser admitido requerente no Inventario para occorrer a algum conluio que se faça em seu prejuizo.

Se pende demanda entre hum Emphyteuta e hum Terceiro, entre os quais possa haver alguma collusão prejudicial ao senhorio, pode este preveni-la, assistindo na causa. 
Outro específico exemplo se dá no usufructuario, que se na demanda sobre a Causa da propriedade não póde ser ouvido, o deve ser como Assistente."

Com semelhantes exemplos, LoBÃo ampliava o campo da assistência, para torna-la admissível nos casos em que, em razão do prejuízo decorrente, direta ou indiretamente, da sentença proferida na causa entre as partes, era permitido apelar ao terceiro que não participara do feito. Esclarece LOB.̃̃o:

"A razão da Ord. L. 3 Tit. 78 1, authorisa todos estes e semelhantes casos, a que podem juntar-se os especificados na Ord. L. 3 Tit. 81, e semelhantes; porque se elles podem appellar depois das Sentenças, que directa e indirectamente lhe são prejudiciaes, ou o podem ser, proferidas em demandas entre Terceiros, segue-se que, "melius est ante tempus occurrere, quam post remedium quoerere." 42

11. Foi êsse, em linhas gerais, o sistema jurídico que disciplinou a assistência, no regime das Ordenações Filipinas.

No Brasil, proclamada a independência, a lei de 20 de outubro de 1823, emanada da Assembléia Constituinte, dispôs que continuariam em vigor as Ordenações do Reino, Leis, Regimentos, Alvarás, Decretos e Resoluções promulgadas pelos Reis de Portugal, e pelas quais se governava o País até o dia 25 de abril de 1821, enquanto se não organizava um novo Código, ou não fôssem especialmente alteradas. ${ }^{43}$

As Ordenações Filipinas, assim, estiveram em vigor, disciplinando o processo das ações cíveis e comerciais, até o advento do Regulamento $n .^{\circ} 737$, de 25 de novembro de

42. Manoel de Almeida e Sousa, De Lobão, op. cit. p. 48.

43. Cf. Candido Mendes de Almeida, "Codigo Philippino", 14.a ed. Rio 1870, Prefácio p. xxxvi. 
1850; a partir dessa data, sua aplicação restringiu-se às ações cíveis, até que, pelo Decreto $\mathrm{n}^{\circ}$ 763, de 19 de setembro de 1890 , foi mandado observar no processo das causas cíveis, em geral, o Regulamento 737, com algumas exceções.

Dessa forma, o Livro Terceiro das Ordenações Filipinas deixou de vigorar, no Brasil, como o estatuto do processo civil, em fins do ano de 1890 , ao se iniciar o regime republicano. 